one example from each of the main branches of earth science.

The book should form an excellent basis for a very elementary course (even less than the prescribed 40 hours) as it not only covers the basic concepts but also gives ample warnings of the standard pitfalls into which so many senior earth scientists have fallen-and are still falling. To quote one example, not used in the book, radioactive isotopic dates invariably include their precision, that is, the repeatability, yet most earth scientists still take these figures as measures of accuracy, at least until they conflict with their own ideas.

Other credits are good references and the avoidance of that frustrating phrase "it can be shown that"; instead Dr Till refers the neader elsewhere, usually to Yule and Kendall, for a more rigorous explanation but even that is rare. The publishers also deserve credit as the book is well produced and designed, although certain figures (for instance, 5.5, 5.6 and 5.7) are really too big and, if reduced, would not only have saved paper but would also have improved the appearance of the book.

The index covers only statistical subjects, and it might sometimes be necessary to find out where porosity or grain size is considered. But the only real fault is the scope: the range of analyses covered is much too short for the cost of the book and it would also have been a better buy if more statistical tables had been included.

I hope that Dr Till will be encouraged to expand this introductory text to include, for example, much fuller consideration of directional properties so that this book, if still sold at the same price, could become an essential text at the start of any earth scientist's career. But at the moment it does not go far enough.

\section{Model methods}

Analytical Methods in Planetary Boundary-Layer Modelling. By R. A. Brown. Pp. xii $+148+5$ plates. (Adam Hillger: London, June 1974.) $£ 8.00$.

THE scope of this book is narrower than one might guess from the title. It deals primarily with a restricted topic in the theory of the Earth's atmospheric boundary layer, namely the mean velocity distribution in stationary, horizontally homogeneous, and neutrally stratified conditions. Particular emphasis is placed on the matching of an upper Ekman layer with a surface layer unaffected by the Earth's rotation. Concluding chapters consider the effects of non-neutral stratification and non-stationarity, but the treatment is very superficial. There are also two chapters on the instability of Ekman layers and the relationship between that and meteorological observations; this is the best part of the book but its connection with the rest is not made clear.

For whom is this book intended? The author offers no indication, and the level of difficulty is so variable that one cannot guess. Who is the mysterious reader who can comprehend the equations of fluid motion with no derivation and little explanation, but who requires an elementary explanation of the procedures of dimensional analysis; who is already familiar with the properties of geostrophic flow, but not with the basic derivation of centripetal and Coriolis accelerations; who knows what is meant by "the eddy flux of potential heat", but who can usefully read a most superficial summary of the properties of thermal convection?

Meteorology students might benefit from a text leading up to current views of the atmospheric boundary layer through explanation of the now classical topics of Ekman layer theory and micrometeorology; synthesis of those topics is not so commonly discussed. Brown's book is, however, neither comprehensive enough nor lucid enough

\section{There's still no place like Holmes}

Earth. (A series of books in Geology.) By F. Press and R. Siever. Pp. xi+945. (W. H. Freeman: San Francisco, July 1974.) $£ 6.60$.

THE authors of this book have impeccable qualifications for writing it, both as active research scientists and as university teachers. They say that it is intended for students who have had no previous college science courses; and they express the hope that it is as up to date as a current meeting of the Geological Society of America (it was finished in December 1973) and that at the same time, it is as understandable as today's newspaper. These intentions are commendable and the task they have set themselves is difficult; it is interesting to see how they tackle it.

The level throughout the book, which is splendidly produced and illustrated, is such that after reading it the diligent student should experience no difficulty with specialist papers in Scientific American. Plate tectonics figures large and early. The first 150 pages-"The earth as an historically evolved body and how we study it"-serve to introduce the vocabulary. They start with an account of the origin of the Solar System, which I found interesting because I knew nothing about it, and finish with a long chapter on rocks and minerals. Part II covers the traditional field of physical geology. Part III introduces the fields of petrology and geophysics and this section is written at a marginally higher level than the others; for example, a chapter on the to serve that purpose. The derivation of the well known logarithmic profile, for instance, would be quite incomprehensible to anyone not already familiar with it.

Errors in the equations and algebraic expressions are sufficiently numerous to provide further reason for not recommending the book to readers unfamiliar with the subject. Most of the errors are probably misprints (although there are too many of them for this to be acceptable as an excuse). But there are incorrect signs on pages 49 and 79 which invalidate the subsequent algebra; and equation (3.19) is, I suspect, a misprinted version of an incorrect equation.

Research workers in fluid dynamics and meteorology may occasionally find the book a useful source on those topics for which the information is not gathered together elsewhere. But this purpose could have been fulfilled more effectively and economically by a review article on, for example. 'Ekman layers in meteorology'.

D. J. Tritton

formation of igneous rocks touches on Bowen's reaction series and on the problem of the origin of granite batholiths. I wonder, however, whether the 27 pages on plutonism and metamorphism really equip the reader to dip into F. J. Turner's book Metamorphic Petrology which is quoted in the bibliography.

How, then, does the book live up to its authors' intentions? Trying to cope with a readership which is assumed to be entirely without any scientific education has made the book unmanageably long. Was it necessary to devote three pages (115-118) to defining words like topography and contour? The need to start the chapter on weathering with the very beginning of inorganic chemistry makes it impossible to discuss the peculiarities of the weathering of rocks at all. The desire to encompass past present and future in one large sweep reminds me of the phrenetic enthusiasm of geophysicists running an open day in the laboratory. For example, in chapter 3 ("How we find out about the earth") we have a photograph of a Benioff strain seismometer, a section on experimental petrology and a 'box' about Cavendish's 1798 determination of $G$, together with 15 other topics all introduced in the course of 22 pages. The book is certainly not dull, but I wonder whether the American college student has the stamina to read its 945 pages. I do know that the English girl studying for ' $A$ ' levels on whom I tried it, had not. In this field Holmes remains ancient but unbowed.

D. H. Matthews 